\title{
SÍNDROME DE BURNOUT - ESTRATÉGIAS, RECONHECIMENTO E PREVENÇÃO NO CONTEXTO ORGANIZACIONAL
}

\section{ARTIGO ORIGINAL}

SILVA, Lucas Soares da ${ }^{1}$

SILVA, Marinalva Dias da ${ }^{2}$

PEREIRA, Natacha Maiara ${ }^{3}$

SCATOLIN, Henrique Guilherme ${ }^{4}$

SILVA, Lucas Soares da. Et al. Síndrome de Burnout - Estratégias, reconhecimento e prevenção no contexto organizacional. Revista Científica Multidisciplinar Núcleo do Conhecimento. Ano 05, Ed. 11, Vol. 18, pp. 166-180. Novembro de 2020. ISSN: 2448-0959, Link de acesso: https://www.nucleodoconhecimento.com.br/psicologia/reconhecimento-eprevencao

\section{RESUMO}

A relação humana com o trabalho, presente há muito tempo, tem sido considerada pelo homem como fator determinante para sua identificação pessoal. Porém, no

1 Pós Graduação em Psicologia Organizacional e do Trabalho e Graduação em Gestão de Recursos Humanos.

2 Graduação em Direito e Pós Graduação em Psicologia Organizacional e do Trabalho.

${ }^{3}$ Graduação em Psicologia e Pós Graduação em Psicologia Organizacional e do Trabalho.

${ }^{4}$ Orientador. Graduação em Psicologia pela Unimep, mestrado, doutorado e pósdoutorado pela PUC SP. 
contexto atual das organizações, em que a pressão psicológica e estresse são fatores predominantes das atividades profissionais, os indivíduos são passíveis de desenvolvimento de patologias ligadas ao sofrimento no trabalho como o estresse, a ansiedade, as doenças psicossomáticas e a síndrome do Burnout. O objetivo da presente pesquisa é realizar uma revisão de literatura que nos permita refletir sobre o preparo das empresas para o reconhecimento da síndrome de Burnout nos indivíduos e o devido encaminhamento para o profissional da saúde habilitado para o diagnóstico e tratamento. O estudo realizado analisou como as empresas, em sua atuação, contribuem diretamente para o aparecimento e prevenção da doença. Utilizando métodos de pesquisa de revisão bibliográfica sobre o tema, o trabalho gera um questionamento sobre se as empresas estão qualificadas para o acolhimento, reconhecimento, direcionamento e reintegração de colaboradores que apresentam sintomas claros da doença. Após levantamento de informações observa-se que evidentemente o tema na área organizacional tem sido desprezado pela comunidade cientifica, o que mostra o despreparo das organizações para cuidar de pessoas com a Síndrome de Burnout.

Palavras-Chave: Burnout, estresse, cultura organizacional.

\section{INTRODUÇÃO}

O trabalho ocupa grande parte do tempo do dia e do convívio em sociedade das pessoas. Ao longo dos anos, ele vem sofrendo grandes mudanças desde a Reforma Industrial, o que também impactou no sentido que o trabalho passa a ter para o sujeito (DEJOURS, 1992).

Nos dias atuais, com a globalização e a evolução dos recursos tecnológicos, exercer uma profissão é muito mais do que apenas uma forma de ganhar dinheiro para suprir as necessidades diárias. Ele se torna a identidade do sujeito. Em muitos casos, sua função irá se tornar seu rótulo, aquilo que traz identificação para os humanos; mas no mundo organizacional, as cobranças e exigências são cada vez maiores e consequentemente há uma busca por uma mão de obra cada vez mais especializada, 
com formação acadêmica, cursos complementares, idiomas, anos de experiência na área, e pouco se fala na saúde mental desses trabalhadores, dentro de um contexto de tanta pressão por resultados. A relação que os humanos mantem com o trabalho, passam a ser o foco central de uma gama de conflitos e a saúde mental, inevitavelmente, passa a ter algum prejuízo. Esse estresse contínuo resulta em um desiquilíbrio cognitivo, não havendo brechas para a capacidade criativa e de sublimação. (GUIMARÃES e GRUBITS,2000).

Nesse contexto de aumento de pressão e nível de exigências relacionadas a sua atividade profissional, o indivíduo é submetido diariamente a situações de estresse que acabam desencadeando doenças, tais como ansiedade, síndrome do pânico, alcoolismo, dependência química, estresse e em casos extremos a Síndrome de Burnout. (SILVA, 2000). O Burnout é uma doença que exclusivamente tem relação com o trabalho.

O termo, ao longo dos anos, adquiriu várias nomenclaturas diferentes, sendo elas: "fadiga laboral", "estresse ocupacional" ou "estresse profissional". Mesmo assim, nenhuma delas foi tão utilizada quanto o Burnout devido a predominância da expressão inglesa que passou a ser utilizada em vários países. (PEREIRA, 2002).

Segundo Codo e Vasques-Menezes (1999), o termo "Burnout" em português se assemelha a "expressão": algo que perdeu sua energia. Para esses autores o Burnout ocorre quando o trabalho começa a perder o seu real sentido para o indivíduo, ou seja, o trabalho se torna um processo exaustivo e desgastante como se qualquer ação se tornasse inútil no contexto. É uma síndrome que pode acometer todo e qualquer tipo de trabalhador em todas as áreas de atuação, e envolve três fatores, sendo eles exaustão emocional, despersonalização e falta de envolvimento pessoal no trabalho.

Portanto, a Síndrome de Burnout é decorrente de uma série de frustrações e ações mal sucedidas no decorrer da trajetória do indivíduo em seu trabalho, gerando então uma exaustão emocional, esgotamento de energias nas tarefas diárias, pensamentos negativos, falta de empatia com suas relações interpessoais, sintomas esses, que se 
não tratados da maneira correta podem chegar ao extremo, se distanciando emocionalmente, tendo ações negativas e rígidas, fazendo com que o indivíduo não consiga mais frequentar seu local de trabalho pelo tamanho do sofrimento que 0 contexto the causa.

A partir da conjuntura acima, o presente trabalho faz uma reflexão sobre o preparo das empresas para o reconhecimento da síndrome de Burnout nos indivíduos e encaminhamento para o profissional da saúde habilitado para o diagnóstico e tratamento. As corporações no âmbito organizacional não têm habilidades e competências necessárias para a análise e intervenção sobre casos de Burnout; porém, em sua atuação contribuem diretamente no aparecimento e prevenção da doença. A problemática que surge nesse contexto é: estão as organizações preparadas para acolher, reconhecer, direcionar e reintegrar colaboradores que apresentam sintomas claros dessa doença ocupacional?

Em adição, este trabalho também tem por finalidade ponderar como a estrutura atual das empresas, em especial os departamentos de Recursos Humanos que estão relacionados a gestão de capital humano, podem se capacitar para agir em conjunto com o ambulatório médico, gestores e direção da empresa no surgimento de casos da patologia.

\section{METODOLOGIA}

A presente pesquisa adotou o modelo de revisão de literatura bibliográfica. Este método "é uma forma de pesquisa que utiliza fontes de informações bibliográficas ou eletrônicas para a obtenção de resultados de pesquisas de outros autores, com o objetivo de fundamentar teoricamente um determinado objetivo" (ROTHER, 2007, p.7). Terá caráter exploratório, que tem como principal objetivo ter uma maior proximidade com o problema exposto pelo estudo, deixando as informações mais claras e compreensíveis, buscando orientar a formulação das hipóteses (GIL, 2010).

A metodologia dessa pesquisa será realizada em três etapas, sendo a primeira a leitura criteriosa e compreensiva do material, a segunda será o levantamento de RC: 71083

Disponível em: https://www.nucleodoconhecimento.com.br/psicologia/reconhecimento-e- 
argumentos, e pôr fim a articulação entre o conteúdo compreendido e a reflexões dos autores. Essas etapas contemplam a necessidade de revisão de procedimentos, estratégias e análises que devem acompanhar um processo de uma pesquisa bem fundamentada (PADUA, 1997).

Pretende-se, por meio desta revisão de literatura, uma reflexão sobre o preparo das empresas para o reconhecimento do Burnout nos indivíduos e encaminhamento para os profissionais da área da saúde que são habilitados para diagnosticar e tratar tal patologia.

A busca de referências foi realizada através das bases eletrônicas de dados, ou seja, SciELO-Brasil, Literatura Americana e do Caribe em Ciências da Saúde (LILACS), PEPSIC e Banco de Teses CAPES. Foram empregadas as palavras-chave: "burnout", "estresse", "adoecimento" e "esgotamento" como os principais critérios de inclusão. Estes foram: (a) livros ou capítulos de livros pertinentes ao tema (a partir do ano 2015) e artigos publicados nas plataformas de pesquisa e selecionados por meio de busca manual no acervo de Psicologia da biblioteca universitária da Fundação Hermínio Ometto - UNIARARAS até março de 2020, e via indicação de bibliografia por especialistas, (b) publicados em língua portuguesa; (c) assunto pertinente ao tema proposto. A pesquisa exclui artigos com o termo burnout que não fazem parte do contexto organizacional antes de 2015.

\section{FUNDAMENTAÇÃO TEÓRICA}

O termo "burnout" ou "burnout" traduzido do inglês é queimar até a exaustão, até não se ter mais energia. Segundo Codo e Vasques-Menezes (1999), a Síndrome de Burnout ocorre quando o trabalho começa a perder o seu real sentido para o indivíduo, ou seja, o trabalho se torna um processo exaustivo e desgastante como se qualquer ação se tornasse inútil no contexto. É uma síndrome que pode acometer todo e qualquer tipo de trabalhador em todas as áreas de atuação, ela envolve três componentes: 
Exaustão Emocional - situação em que os trabalhadores sentem que não podem dar mais de si mesmos a nível afetivo. Percebem esgotada a energia e os recursos emocionais próprios, devido ao contato diário com os problemas.

Despersonalização - desenvolvimento de sentimentos e atitudes negativas e de cinismo às pessoas destinatárias do trabalho (usuários / clientes) - endurecimento afetivo, 'coisificação' da relação.

Falta de envolvimento pessoal no trabalho - tendência de uma 'evolução negativa' no trabalho, afetando a habilidade para realização do trabalho e o atendimento, ou contato com as pessoas usuárias do trabalho, bem como com a organização. (CODO e VASQUES-MENEZES, 1999 p. 239).

Com base nas ideias dos autores acima, a exaustão emocional é decorrente do esgotamento de todos os recursos emocionais afetivos e motivadores no ambiente de trabalho que se estende para a sua vida social nas relações interpessoais. A despersonalização o sujeito passa a encarar suas relações afetivas profissionais e pessoais sem sentimentos, como se fosse algo "mecânico", de forma insensível, tendo um distanciamento das relações pessoais. Por fim a falta de envolvimento pessoal no trabalho, se passa a ter uma relação negativa com o trabalho, ocasionando uma dissimulação, insatisfação, infelicidade e falta de vontade de realizar as tarefas cotidianas. O Burnout é o estado de exaustão proveniente de um contexto organizacional com uma carga elevada de estresse, deixando até suas próprias necessidades de lado (FREUDENBERGER, 1974).

A SB é uma das saídas que uma mente humana encontra ao lidar com o estresse no trabalho. Portanto, para analisarmos a fundo esse evento, é de extrema importância conhecer mais sobre o conceito de estresse. A todo momento somos entregues a situações que promovem o estresse. Tudo que se altera, muda e modifica em nosso ambiente pode trazer à tona algum tipo de estresse. Para uma mãe um bebê chorando, uma atividade de limpeza da casa ou uma nova tarefa podem parecer estressantes. No trabalho, uma nova solicitação do chefe, um e-mail ou uma planilha a ser entregue. Tudo que nos tira do equilíbrio físico, emocional e mental pode gerar 
estresse. Porém se o estresse faz parte do nosso dia a dia, inclusive em situações corriqueiras, por que desenvolvemos doenças a partir dele?

Stress é uma condição de desequilíbrio do funcionamento, tanto físico como mental. Em momentos de tensão excessiva, todo o organismo é afetado. Se este equilíbrio é reestabelecido de pronto, não há danos maiores para a pessoa. No entanto, se a condição de desequilíbrio permanecer por tempo excessivo, as doenças começam a surgir e a impaciência, a ansiedade e a depressão se estabelecem (LIPP, 2010, p.1).

Levando em consideração esse conhecimento teórico, é inegável que o estresse faça parte do dia a dia de todos os seres humanos, mas sua permanência com força excessiva na rotina humana pode desencadear doenças e uma delas seria a Síndrome de Burnout. Em relação ao trabalho, várias coisas podem gerar esse estresse: trânsito, horário e carga horária de trabalho, as pressões por tempo, resultado e a sobrecarga, inadaptação a mudanças organizacionais, sentimento de insegurança, remuneração insatisfatória, gestão autoritária e etc. Lidar todos os dias com todas essas situações pode provocar na mente de um sujeito saudável, estresse repetitivo excessivo e leva várias pessoas ao adoecimento emocional e psicológico.

No contexto organizacional, a Síndrome de Burnout traz consequência nas relações interpessoais, desmotivação do sujeito que interfere também no clima, diminuição da produtividade e da qualidade do serviço prestado, não tendo o mesmo rendimento de antes, aumento do turnover e absenteísmo, desfalque no trabalho e aumento de acidentes do trabalho. (BENEVIDES-PEREIRA, 2003).

A SB está conectada a relação de trabalho e situações de alto estresse para o empregado, seja por uma carga excessiva de trabalho, ou pressão, ou cobrança pessoal ou profissional. Muitas vezes o próprio empregado se cobra tanto para crescer dentro da empresa e acaba não atingindo seu objetivo ou não atinge no tempo em que esperava. Por ser uma doença relacionada ao trabalho é muito importante a atenção da empresa através do $\mathrm{RH}$, cuidar do funcionário, observar o perfil de cada indivíduo dentro da empresa. 
A partir do momento em que perceber algum indicio de alteração comportamental, encaminhar esse empregado para inicialmente uma avaliação com o profissional capacitado para identificar possível SB. Cuidar da qualidade de vida do empregado pela empresa é também cuidar da saúde psíquica, observar os momento e comportamentos do indivíduo dentro do ambiente de trabalho e quando possível fora dele também, estar atendo aos comportamentos nos horários de intervalos, nas festas e confraternizações, percebendo por exemplo um comportamento mais tímido ou recluso no indivíduo que era extremamente comunicativo ou prestativo, podem indicar que algo está errado. Nesse contexto é que se faz muito importante lideres preparados e preocupados com suas equipes, e que ao perceberem o menor sinal de alteração comportamental encaminhe esse empregado para avaliação e tratamento correto quando houver o diagnóstico SB (Válio,2018).

Nas relações de trabalho no que tange o Direito do Trabalho, muitas vezes, as empresas não procuram trabalhar com a prevenção[5] ou não dão a devida atenção para a SB, bem como outras doenças relacionadas a área psíquica dos trabalhadores, para evitar assumir um problema gerado pela carga de trabalho. Ao admitir que esse trabalhador ficou doente dentro dessa relação de trabalho seria assumir um ACIDENTE DE TRABALHO, e com isso todos os encargos trabalhistas e estabilidades que isso gera, sem falar nos gastos com ações trabalhistas e mudanças na cultura da empresa. A função social da empresa é garantir ao trabalhador um ambiente de trabalho sadio, para que durante toda relação de trabalho e após o seu termino ele possa estar apto e com sua saúde física e mental integras como no momento da admissão. Seguindo assim as diretrizes do Art. $7^{\circ}$, inciso XXII, da Constituição Federal de 1988 que diz:

XXII - redução dos riscos inerentes ao trabalho, por meio de normas de saúde, higiene e segurança;

Sendo assim, fica claro a responsabilidade da empresa em assegurar a qualidade de vida do trabalhador por força da nossa Lei maior a Constituição, em que podemos dizer que a prioridade é a dignidade humana na vida social, profissional, familiar. (VÁLIO, 2018).

Disponível em: https://www.nucleodoconhecimento.com.br/psicologia/reconhecimento-e- 
Podemos ainda reforçar essa ideia conforme o autor expõe:

O meio ambiente do trabalho está inserido no meio ambiente geral (art. 200, VIII, da Constituição da República), de modo que é impossível alcançar qualidade de vida, sem ter qualidade de trabalho, nem se pode atingir meio ambiente equilibrado e sustentável ignorando o meio ambiente do trabalho. Dentro desse espírito a Constituição de 1988 estabeleceu expressamente que a ordem econômica deve observar o princípio de defesa do meio ambiente (art. 170, VI). (OLIVEIRA, 2010, p.83)

Pensando nisso, fica claro que cada dia mais é importante que as empresas, organizações estejam alertas e tenham um $\mathrm{RH}$ estruturado para perceber as mudanças significativas de comportamentos dos trabalhadores, é importante falar que apesar de muitas empresas e empregados verem a SB como um tabu ou como algo vergonhoso de assumir que precisa de ajuda, existem empresas que já entenderam que a prevenção traz muitos benefícios em todas as áreas: humana, produtiva, financeira, jurídica e para sua imagem diante dos clientes e empregados.

A empresa que se preocupa com seus empregados, com a qualidade de vida e com o ambiente de trabalho, tende a conseguir melhores resultados e reter seus talentos, podemos aqui citar algumas ações que as empresas podem tomar para melhorar o ambiente de trabalho como: rever as cargas de trabalho e prazos, oferecer ginastica laboral; palestras sobre temas variados; parcerias com academias, clubes, clinicas que oferecem algum tipo de atividade física ou relaxamento; convênios com clinicas de psicologia, dentre outras que possam se adequar a realidade da empresa e que causem efeito no empregado de se sentir à vontade de procurar ajuda quando precisar. Sem desprezar ainda o que nos assegura o art. 157 da CLT, que assegura a proteção para o trabalhador à sua saúde física e psíquica como dever do empregador, conforme segue;

Art. 157. Cabe às empresas: I - cumprir e fazer cumprir as normas de segurança e medicina do trabalho; II - instruir os empregados, através de ordens de serviço, quanto às precauções a tomar no sentido de evitar acidentes do trabalho ou doenças ocupacionais; III - adotar as medidas que Ihes sejam determinadas pelo órgão regional competente; IV facilitar o exercício de fiscalização pela autoridade competente.

Disponível em: https://www.nucleodoconhecimento.com.br/psicologia/reconhecimento-e- 
Com atitudes como essas, as empresas preocupadas com o bem-estar do seu empregado podem direcioná-lo para ajuda especializada para diagnosticar com precisão sua condição e assim receber tratamento adequado, e terá tempo para se preparar para receber esse trabalhador no seu retorno de forma colhedora (VÁLIO, 2018).

\section{ANÁLISE}

O trabalho é algo de extrema importância para nossa sociedade, pois é responsável pela sobrevivência e a realização do ser humano. Sendo o principal agente de mudança da vida psíquica, social, cultural, econômica e política (MALVEZZI, 2004). presente trabalho pretende-se analisar como as empresas, em sua atuação, contribuem diretamente para o aparecimento e prevenção da doença.

No contexto atual, o mercado de trabalho está cada vez mais exigente na contratação de novos funcionários, exigindo quesitos como formação acadêmica, anos de experiências e nem sempre oferecem o salário esperado pelo profissional. Com isso, muitos profissionais são submetidos a diversos fatores estressores que acarretaram ao descontentamento e sucessíveis a síndrome de burnout, esses fatores podem ser: número de horas extras excessivas; insegurança; medo de perder o trabalho e benefícios; ambiente de trabalho sem estrutura adequada; exigência extrema por resultados imediatos; cultura organizacional, entre outros (AREIAS e COMANDULE, 2006).

Sendo assim, a síndrome de Burnout é uma síndrome resultando da "cronificação" dos agentes estressantes do contexto organizacional, tendo consequências a níveis individual, profissional, social e familiar (BENEVIDES-PEREIRA, 2002). No âmbito organizacional, o profissional passa a ter uma diminuição da produtividade, desmotivação no trabalho o que acaba afetando o contexto em que ele está, o que por fim interfere diretamente na vida pessoal do indivíduo.

Para que esse cenário seja evitado nas organizações, são necessários Programas de Qualidade de Vida que irão atuar no desenvolvimento psicológico profissional; 
trabalhar a motivação do indivíduo; ergonomia; criatividade, entre outros aspectos (NASSETA, 2013).

Algumas ações voltadas a QVT foram discutidas na Fundação Europeia para a Melhoria das Condições de Vida e de Trabalho, e destacaram 4 ações essenciais para a melhoria das condições de trabalho, sendo elas:

- Garantir a segurança na carreira e no emprego, assegurando os direitos dos trabalhadores, remuneração adequada e avaliar a situação de trabalho;

- Manutenção e promoção da saúde e bem-estar dos trabalhadores, verificando possíveis problemas de saúde dos funcionários, exposição ao risco e organização do trabalho;

- Desenvolvimento de habilidades e competências, através de treinamentos, palestras, organização de aprendizagem e desenvolvimento de carreira;

- Conciliar vida profissional e não profissional, tempo de trabalho / fora do trabalho e infraestruturas sociais. (EUROPEAN FOUNDATION FOR THE IMPROVEMENT OF LIVING AND WORKING CONDITIONS, 2002, p. 06).

Com isso, as empresas podem implementar um programa de cargos e salários adequado às funções exercidas pelo empregado, essa premissa é importante para a definição das atividades de cada cargo evitando a sobrecarga de funções e a remuneração adequada que são aspectos que motivam a produtividade e a satisfação no trabalho. Priorizar a saúde e bem-estar das pessoas, com projetos de qualidade de vida com promoção e prevenção de saúde. Uma forma de trabalhar preventivamente nesse sentido é a com adequação ergonômica das atividades desempenhadas, evitando que os colaboradores fiquem expostos aos riscos de acidentes e que prejudique sua saúde a médio e longo prazo. As empresas também podem desenvolver parcerias com fisioterapeutas para trabalharem diretamente com a saúde ocupacional e promoção de saúde; promover treinamentos e palestras voltadas a saúde do trabalhador e ao desenvolvimento de carreira. Essas ações 
promovem o aumento da motivação e satisfação dos funcionários com seu trabalho, evitando que adoeçam, além do aumento de sua produtividade.

Outro fato importante para que as organizações deem a devida atenção aos seus trabalhadores é o seu dever jurídico de resguardar a integridade física e psíquica deles visto que seu dever como empregador é o de gerar um ambiente sadio de trabalho, que é a sua obrigação natural diante do contrato de trabalho. Todo trabalhador tem esse direito garantido na Constituição Federal em seu art. 7º , inciso XXII:

Art. $7^{\circ}$ São direitos dos trabalhadores urbanos e rurais, além de outros que visem à melhoria de sua condição social:

XXII - redução dos riscos inerentes ao trabalho, por meio de normas de saúde, higiene e segurança;

Melhorando a Qualidade de Vida no trabalho com programas de prevenção que possam ajudar o trabalhador aliviar a pressão sofrida no trabalho, tudo isso se tornará positivo no desempenho de suas atividades, e com isso evitar o adoecimento que poderá ser considerado como Acidente de trabalho, que pelo Decreto Lei 6042/07 de 12 de fevereiro de 2007, passou a tratada a Síndrome de Burnout como doença profissional equiparada ao acidente de trabalho.

Podemos considerar que todas as profissões estão suscetíveis ao desencadeamento da SB, no entanto conforme pesquisas apontam que está se desenvolve com maior frequência nas profissões que exige altas responsabilidades, contato interpessoal intenso e elevada carga pressão, podemos destacar profissões como as de: gestores, atendentes, vendedores, telemarketing, entre outros (VÁLIO, 2018).

Ainda segundo Válio (2018), a Síndrome de Burnout é desencadeada por atividade laboral desfavorável e para uma ação de prevenção eficaz, seria preciso enfatizar essa ação em 3 níveis que seriam:

a) Programas centrados na resposta do indivíduo: criam-se condições de o indivíduo ter respostas para as situações negativas ou estressantes, sem focar nos elementos inerentes à sua ocupação. (Síndrome de Burnout e a responsabilidade do empregador, 2018, pg 95);

Disponível em: https://www.nucleodoconhecimento.com.br/psicologia/reconhecimento-e- 
Seguindo nessa linha, o primeiro nível seria o de programas compostos por uma equipe multidisciplinar que possa atender de forma individual e ajudar o indivíduo compreender o que está se passando com ele nesse momento, e ajudar a lidar com as situações do dia a dia.

b) Programas centrados no contexto ocupacional: é totalmente voltado aos aspectos organizacionais, buscando a melhora das condições no ambiente de (Síndrome de Burnout e a responsabilidade do empregador, 2018, p. 95);

No segundo nível temos programas voltados ao ambiente de trabalho e como isso influencia na sua forma de sentir e lidar com a pressão, pequenas ações como por exemplo um olhar voltado para ergonomia do ambiente que trabalho pode fazer a diferença, a implantação de ginastica laboral por ser um exemplo.

c) Programas centrados na interação do contexto ocupacional e o indivíduo: neste, o Burnout é visto como u m fruto da relação do indivíduo com o meio Busca-se, assim, combinar os dois níveis anteriores, tentando modificar as condições laborais em detrimento da percepção do trabalhador com a finalidade de também modificar a forma de enfrentamento do indivíduo ante as situações de estresse ocupacional. (Síndrome de Burnout e a responsabilidade do empregador, 2018, p. 96).

Considerando assim o terceiro nível do programa de a prevenção da SB proposto por Válio (2018), um programa para o coletivo, reconhecendo o problema e seus fatores desencadeadores ou fatos geradores, criando estratégias de enfrentamento e buscando profissionais qualificados para atuar diretamente no meio organizacional, e com isso melhorar o ambiente de trabalho e seus reflexos negativos no trabalhador.

Além de todos esses benefícios relacionados ao indivíduo e a própria companhia pelo cumprimento de seu papel como parte da economia regional, é de fato muito importante mencionar a relevância da prevenção da Síndrome de Burnout para a sociedade. O Exercício da prevenção dela traz muitas vantagens, sendo apenas algumas delas: aumento da qualidade de vida das pessoas, diminuição do uso de medicamentos potencialmente perigosos utilizados por pessoas que auto se medicam e fortalecimento das organizações perante sua classe trabalhadora. E indiretamente

Disponível em: https://www.nucleodoconhecimento.com.br/psicologia/reconhecimento-e- 
ainda contribuir com: aumento de emprego da classe de trabalhadores relacionada a prevenção, diminuição do número de acidentes de trabalho, e criação de base legal para a área jurídica quanto a possíveis passivos trabalhistas.

Indiscutivelmente as empresas só receberiam benefícios ao promover programas de prevenção de doenças como a SB., Porém no sistema econômico atual, entende-se gastos relacionados a prevenção de doenças nas organizações como mera formalidade e até mesmo gastos desnecessários. Porém mesmo que nossa realidade econômica limite uma grande parte dos empregadores, muitos programas de prevenção podem e devem ser desenvolvidos, com baixo ou nenhum custo às empresas.

Mencionando essa responsabilidade das organizações, Osmir (2004) comenta que, cabe ao administrador procurar e desenvolver promoções a saúde mental, como parte de suas atividades relativas à saúde e a segurança no trabalho e a partir disso viabilizar a melhora da saúde mental e compreender o combate aos transtornos mentais neutralizando os fatores que podem favorecê-los e assim manter um ambiente adequado longe das doenças ocupacionais.

\section{CONCLUSÃO}

A pesquisa teve como finalidade trazer uma reflexão sobre a síndrome de Burnout no contexto organizacional e como essas empresas podem lidar com os funcionários que infelizmente estão acometidos com a síndrome, e principalmente como prevenir e promover um ambiente de trabalho saudável, através de projetos de qualidades de vida, desenvolvimento individual, treinamentos e principalmente ter uma atenção especial nos funcionários que tiveram uma queda significativa da produtividade ou demonstra uma desmotivação que não era caraterística e pensar em intervenções para melhorar a qualidade de vida desse funcionário.

Após esse estudo, é possível comparar a realidade das organizações com a real necessidade sobre o tema, e claramente pode-se afirmar que as empresas do âmbito organizacional não estão preparadas para esse reconhecimento. Seu principal

Disponível em: https://www.nucleodoconhecimento.com.br/psicologia/reconhecimento-e- 
objetivo tem sido o lucro financeiro, e a saúde dos colaboradores tem sido deixada para terceiro ou quarto lugar. Esse comportamento autodestrutivo das organizações levará a um futuro sombrio, empresas cheias de pessoas doentes e que mal sabem lidar com o mal que as acometem e isso não somente no Brasil, mas em nível global.

Esse estudo, contudo, além de mostrar o despreparo das organizações é um incentivo para que elas se adequem com ambulatórios, programas de qualidade de vida, e recebam aos benefícios relacionados a saúde emocional e psicológica das pessoas. Aumento de produtividade, melhor performance e engajamento profissional é o resultado de trabalhos voltados a área da saúde cognitiva nas organizações. Compreende-se que é necessário trabalhar e pensar na saúde e bem-estar do funcionário e promover um ambiente de trabalho saudável, pois é no trabalho que o indivíduo vive grande parte da sua vida.

Por fim, no Brasil infelizmente ainda há poucos estudos publicados sobre a síndrome de Burnout, principalmente voltados ao contexto organizacional e nas estratégias de como o empregador pode identificar que estão com essa condição, bem como prevenir e promover um ambiente de trabalho adequado. Esse trabalho institui uma crítica ao tema que é pouco explorado mesmo sendo tão importante falar sobre e pouco observado pelas organizações. Portanto não esgotamos todas as possibilidades de estudo referentes no âmbito organizacional e por isso há a necessidade de novos autores e estudos que abordem a Síndrome de Burnout para que no futuro tenhamos evoluído com relação a saúde dos trabalhadores.

\section{REFERENCIAS BIBLIOGRAFICAS}

AREIAS, C. S; COMANDULE, A. Q., Qualidade de vida, estresse no trabalho e síndrome de burnout. 2006 Campinas, SP. IPES Editorial. Disponível em: https://www.fef.unicamp.br/fef/sites/uploads/deafa/qvaf/fadiga_cap13.pdf. Acesso: 28 de abril de 2020. 
BENEVIDES-PEREIRA, A. M. T. Burnout: quando o trabalho ameaça o bem-estar do trabalhador. 2002 São Paulo: Casa do Psicólogo, 2002. Disponível em: . Acesso em: 15 de abril de 2020.

Codo, W., \& Vasques-Menezes, I. (1999). O que é burnout? Em W. Codo (Org.), Educação: Carinho e trabalho (pp. 237-255). Rio de Janeiro: Vozes. Disponível em:http://portaldoprofessor.mec.gov.br/storage/jornaldoprofessor/midias/arq/Burnout. pdf Acesso: 29 de abril de 2020.

CARLOTTO, Mary Sandra; CÂMARA, Sheila Gonçalves. Análise da produção científica sobre a Síndrome de Burnout no Brasil. PSICO, Porto Alegre, PUCRS, v. 39, n. 2, pp. 152-158, abr./jun. 2008.

DEJOURS, C. - A loucura do trabalho. Cortez-Oboré, São Paulo, 1992 European Foundation for the Improvement of Living and Working Conditions, 2002. Quality of work and employment in Europe: Inssuses and challenges, №1. Dublin, Ireland. Disponível em: https://www.eurofound.europa.eu/sites/default/files/ef_files/pubdocs/2002/12/en/1/ef0 212en.pdf Acesso: 28 abril de 2020

FIORELLI, Osmir. Psicologia para administradores: integrando teoria e prática. 4 ed. São Paulo: Atlas, 2004.

FREUDENBERGER, H. J. Staff burn-out. Journal of social issues, Malden, v. 30, no. 1, p. 159-165, 1974.

GIL, A. C.. Como elaborar projetos de pesquisa. 5 ed. São Paulo: Atlas, 2010 GUIMARÃES, L.A.M; GRUBITS, S. (org) Série Saúde Mental Vol.1. São Paulo: Casa do Psicólogo (2001). 
LIPP, Marilda Novaes. Stress na atualidade: qualidade de vida na família e no trabalho. 2010. Disponível em: <http://www.estresse.com.br/publicacoes/stress-naatualidadequalidade-de-vida-na-familia-e-no-trabalho/>. Acesso em: 20 abril 2020.

MALVEZZI, S. Prefácio. Psicologia, Organizações e Trabalho no Brasil. Organizadores: Zanelli, J,C,; Boges-Andrade, J.B. e Bastos, AA.V.B. Porto Alegre, Artmed, 2004

MINAYO, M. C. S. O desafio do conhecimento: pesquisa qualitativa em saúde. 12. Ed. São Paulo: Hucitec, 2010.

NASETTA, S. A., Percepción de calidad de vida profesional en trabajadores de la salud. Alternativas en Psicología. Revista Semestral. Tercera Época. Año XVII. Número 28. Febrero-Julio 2013. Disponível em: http://pepsic.bvsalud.org/pdf/alpsi/v17n28/n28a01.pdf. Acesso: 28 de abril de 2020.

OLIVEIRA, Sebastião Geraldo de. Proteção Jurídica à Saúde do Trabalhador. 6ª̣ed. São Paulo:

$\mathrm{LTr}$, 2010. http://uniesp.edu.br/sites/_biblioteca/revistas/20190312105103.pdf

PÁDUA, Elisabete Matallo M. de, Metodologia da Pesquisa: Abordagem TeóricoPrática $18^{\circ}$ Edição, 1997

PEREIRA, Ana Maria T Benevides. Casa do psicólogo. Quando o trabalho ameaça o bem-estar do trabalhador, 2002.

ROTHER, E. T. Revisão sistemática $X$ revisão narrativa. Acta paulista de enfermagem. São Paulo, v. 20, n. 2, p. v-vi, jun. 2007. Disponível em: $<$ http://www.scielo.br/scielo.php?script=sci_arttext\&pid=S010321002007000200001 > Acesso em: 02 de abril de 2020.

SILVA.S.B.F. Síndrome De Burnout: Consequência Depressiva Desencadeada Pelo Estresse No Trabalho. Publicado em: 18/01/2010. Acesso em: 17 abril 2020. Disponível em: <http://www.artigonal.com/saude-artigos/sindrome-de-

Disponível em: https://www.nucleodoconhecimento.com.br/psicologia/reconhecimento-eprevencao 
burnoutconsequencia-depressiva-desencadeada-pelo-estresse-no-trabalho1744128.html>

SILVA, F. P. P. Burnout: um desafio a saúde do trabalhador. PSI- Resvista de Psicologia Social e Institucional, v. 2, n. 1, jun. 2000.

SILVA. F.P.P. Burnout: Um desafio à saúde do trabalhador. Rev. de Psicologia. v. 2. n.01. Jun/2000. Acesso em: 07 abril 2020. Disponível em: <http://www.uel.br/ccb/psicologia/revista/textov2n15.htm> https://repositorio.ufrn.br/jspui/bitstream/123456789/17443/1/EtienneAMD.pdf acessado em 21/03/2020

TRIGO, T. R.; TENG, C. T.; HALLAK, J. E. C. Síndrome de burnout ou estafa profissional e os transtornos psiquiátricos. Rev. psiquiatr. clín., São Paulo, v. 34, n. 5, 2007 . Acesso: em: 09 abril 2020 Disponivel em: <http://www.scielo.br/scielo.php?script=sci_arttext\&pid=S010160832007000500004\& Ing=en\&nrm=isso>

VÁLIO, Marcelo Roberto Bruno Síndrome de Burnout e a responsabilidade do empregador / Marcelo Roberto Bruno Válio. — São Paulo: LTr, 2018.

\section{APÊNDICE - REFERÊNCIA DE NOTA DE RODAPÉ}

5. Essa reflexão sobre a prevenção será aprofundada em nossa análise.

Enviado: Maio, 2020.

Aprovado: Novembro, 2020. 